\title{
Determinação de cálcio "trocável» em solos por fotometria e chama $(+(++)$
}

\author{
R. A. CATANI e N. A. DA GLORIA
}

Escola Superior de Agricultura aLuiz de Queiroz»

- Trabalho executado com aparelhamento doado pela Fundação Rockefeller.

* Recebido para publicação em 26/6/1963. 


\section{INTRODUÇÃO}

A determinação do cálcio "trocável" em solos se reveste de elevada importância, quando se considera que o citado cátion contribui com cêrca de $80 \%$ do teor de bases trocáveis de muitos solos.

A extração do teor "trocável" de cálcio dos solos do Estado de S. Paulo, pode ser feita com solução 0,05 normal de $\mathrm{HNO}_{3}$, uma vez que os dados assim obtidos, são equivalentes aos fornecidos quando se faz a extração com solução normal de acetato de amônio, com $\mathrm{pH}=7$ (CATANI \& KUPPER. 1949).

O método analitico mais usado para a determinação do cálcio em solos, e em outros materiais, é o baseado na titulação do ácido oxálico, procedente do oxalato de cálcio, com permanganato de potássio. Apesar dêsse método oferecer precisão e exatidão elevadas, a sua morosidade tem levado muitos pesquisadores a investigarem métodos mais rápidos.

Dentre os métodos rápidos de determinação do cálcio "trocável", o baseado na fotometria de chama tem merecido a atenção de diversos autores, conforme cita BURRIEL MARTI \& RAMIREZMUÑOZ (1957). Entretanto, o método de determinação de cálcio por fotometria de chama tem apresentado uma certa dificuldade na obtenção de dados precisos e exatos, em virtude da interferência de diversos ions. Assim, a presença dos íons aluminio, fosfato, ferro e manganês nos extratos de solos, tornam necessário um tratamento prévio da solução, com a finalidade de atenuar ou eliminar as interferências provocadas pelos citados ions (DINNIN, 1960; PRATT \& BRADFORD, 1960; WILLIAMS, 1960).

$O$ objetivo do presente trabalho foi estudar a determinação do cálcio trocável, por fotometria de chama, em solos do Estado de São Paulo, procurando eliminar ou atenuar as interferências de diversos ions.

\section{MATERIAL E MÉTODOS}

O material constituiu-se de 10 amostras de solos de diversos tipos, cujas cracterísticas são apresentadas no quadro 1. Tais caracteristicas foram obtidas, segundo métodos já descritos (CATANI, GALLO \& GARGANTINI, 1955). 


\section{QUADRO 1}

Características dos solos usados para o estudo da determinação do cálcio por fotometria de chama.

Em $100 \mathrm{~g}$ de terra fina sêca ao ar

\begin{tabular}{|c|c|c|c|c|c|c|c|}
\hline \multirow{2}{*}{$\begin{array}{c}\text { Terra } \\
\text { n. }{ }^{\circ}\end{array}$} & \multirow[b]{2}{*}{$\mathrm{pH}$} & \multicolumn{2}{|c|}{$\begin{array}{l}\text { teor total } \\
\text { em } \mathrm{g}\end{array}$} & \multicolumn{4}{|c|}{ teor trocável em e.mg } \\
\hline & & $\mathrm{C}$ & $\mathrm{N}$ & $\mathrm{K}^{+}$ & $\mathrm{Mg}^{++}$ & $\mathrm{H}^{+}$ & $\mathrm{e} \mathrm{mg} *$ \\
\hline 1 & 6,20 & 1,59 & 0,153 & 0,12 & 0,63 & 4,65 & 0,04 \\
\hline 2 & 6,10 & 1,46 & 0,154 & 0,10 & 0,60 & 4,70 & 0,09 \\
\hline 3 & 5,10 & 0,71 & - & 0,05 & - & - & 0,03 \\
\hline 4 & 5,85 & 0,45 & 0,080 & 0,23 & - & 3,13 & 0,13 \\
\hline 5 & 6,60 & 0,62 & 0,130 & 0,20 & 0,70 & 1,61 & 0,29 \\
\hline 6 & 6,75 & 1,10 & 0,180 & 0,18 & 2,05 & 3,39 & 0,22 \\
\hline 7 & 5,40 & 0,88 & 0,083 & 0,18 & 0,42 & - & 0,31 \\
\hline 8 & 4,90 & 1,37 & 0,210 & 0,11 & 0,43 & 3,84 & 0,07 \\
\hline 9 & 4,80 & 1,06 & 0,081 & 0,20 & 0,23 & - & 0,81 \\
\hline 10 & 5,20 & 0,80 & 0,059 & 0,21 & 0,46 & - & 0,54 \\
\hline
\end{tabular}

* Solúvel em $\mathrm{H}_{2} \mathrm{SO}, \mathrm{O}, \mathrm{O} 5 \mathrm{~N}$

O aparelho usado foi um fotômetro de chama Coleman, modêlo 21 , com filtro para cálcio. Usou-se chama de butano e oxigênio, com a pressão de gases regulada em 2 e 10 psi respectivamente.

\section{Reativos:}

Dos reativos usados, os que merecem menção especial são os seguintes:

Solução padrão de cálcio - Preparada a partir de $\mathrm{CaCO}_{3}$ p.a.. Foram dissolvidos $1,250 \mathrm{~g}$ do sal em ácido nítrico diluido, deixou-se secar completamente e a seguir o resíduo foi dissolvido em água destilada, completando-se o volume a $500 \mathrm{ml}$. A solução assim preparada contendo $1000 \mathrm{ppm}$ de $\mathrm{Ca}$, constituiu a solução estoque. 'Por diluição da mesma com água destilada, foram preparađas as soluções padrões de menor concentração.

Solução padrão de ferro - Preparada a partir da solubilização de $\mathrm{Fe}_{2} \mathrm{O}_{3}$ p.a. em $\mathrm{HCl}$.

Solução padrão de alŭminio - Preparada a partir do Al metálico dissolvido em $\mathrm{HCl}$. 
Solução padrão de fosfato - Preparada a partir de $\left(\mathrm{NH}_{4}\right)_{2} \mathrm{HPO}_{4}$ p.a.

As soluções padrões de magnésio, manganês, potássio e sódio foram preparadas a partir dos respectivos cloretos.

\section{Métodos:}

Relação entre leituras no fotômetro e concentração em cálcio.

A relação entre leituras no galvanômetro do aparelho e a concentração em cálcio, foi estabelecida a partir de soluções aquosas e soluções $0,02 \mathrm{~N}$ e $0,05 \mathrm{~N}$ em $\mathrm{NH}_{4} \mathrm{NO}_{3}$. O estudo da determinação do cálcio em presença de $\mathrm{NH}_{4} \mathrm{NO}_{3}$ apresenta interêsse porque a extração do cálcio do solo é executada com solução de $\mathrm{HNO}_{3}$, que é neutralizada com $\mathrm{NH}_{4} \mathrm{OH}$, resultando o mencionado sal.

As soluções aquosas de padrões de cálcio, foram preparadas da seguinte maneira: foram transferidos $1,2,3,4$ e $5 \mathrm{ml}$ da solução estoque de cálcio, contendo $1000 \mathrm{ppm}$ do elemento, para balōes de $50 \mathrm{ml}$ e o volume foi completado com água destilada. Obtiveram-se assim soluções $0,001 \mathrm{~N}, 0,002 \mathrm{~N}, 0,003 \mathrm{~N}, 0,004 \mathrm{~N}$ e $0,005 \mathrm{~N}$ em cálcio, respectivamente.

O nitrato de amônio foi preparado pela neutralização de $\mathrm{HNO}_{3}$ pelo $\mathrm{NH}_{4} \mathrm{OH}$ de modo a se obter solução $0,02 \mathrm{~N}$ e $0,05 \mathrm{~N}$ em $\mathrm{NH}_{4} \mathrm{NO}_{3}$. Os padrões de cálcio foram adicionados e assim foram obtidas soluçōes $0,001 \mathrm{~N}, 0,002 \mathrm{~N} \ldots$ etc., até $0,005 \mathrm{~N}$ em cálcio, em solução $0,02 \mathrm{~N}$ e em solução $0,05 \mathrm{~N}$ em $\mathrm{NH}_{4} \mathrm{NO}_{3}$.

As leituras foram feitas com o aparelho ajustado de maneira a se obter uma leitura 100 , queimando-se a solução pura $0,005 \mathrm{~N}$ em cálcio e o zero da escala do aparelho foi obtido com água destilada.

Influência de diversos ions sôbre a determinação do cálcio.

$O$ estudo da influência dos diversos cátions e ânions, sôbre a determinação do cálcío, foi feito adicionando-se à solução $0,02 \mathrm{~N}$ em $\mathrm{NH}_{4} \mathrm{NO}_{3}$, com e sem cálcio, quantidades conhecidas de padröes dos íons interferentes. Os dados assim obtidos foram comparados com os determinados em soluções isentas de ions interferentes.

Determinação do cálcio "trocável".

A extração do cálcio foi feita na proporção de $10 \mathrm{~g}$ de solo para $100 \mathrm{ml}$ de $\mathrm{HNO}_{3} 0,05 \mathrm{~N}$, com agitação durante 15 minutos (CATANI, GALLO \& GARGANTINI, 1955).

Tôdas as amostras de terra estudtdas foram pesadas cinco vêzes para a determinação do cálcio, pelo método permanganomé- 
trico e cinco vêzes, para a determinação do citado elemento pelo fotômetro de chama. A determinação do cálcio pelos dois métodos, foi feita após precipitação dos íons ferro, alumínio, manganês e fosfato, por hidróxido de amônio e água de bromo, conforme CATANI, GALLO \& GARGANTINI (1955) .

No caso especial da determinação por fotometria de chama, foram tomados 20 ou $40 \mathrm{ml}$ do extrato do solo, conforme se tratasse de um solo com maior ou menor quantidade de cálcio "trocável", e após a eliminação por precipitação, de ferro, alumínio, manganês e fósforo, o volume foi completado a $50 \mathrm{ml}$.

As leituras foram feitas com o aparelho ajustado para a leitura 100 , com solução $0,005 \mathrm{~N}$ em cálcio, de acôrdo com o teor de cálcio "trocável" do solo.

A relação entre as leituras obtidas no aparelho e as concentrações em cálcio foi linear quando se empregou como referência, quer a solução $0,001 \mathrm{~N}$ como a solução $0,005 \mathrm{~N}$ em cálcio. Dêsse modo, as leituras do aparelho foram convertidas em e.mg $\mathrm{Ca}^{+}$ por $100 \mathrm{~g}$ de solo, multiplicando-se apenas por um fator.

\section{RESULTADOS OBTIDOS E DISCUSSÃO}

\subsection{INFLUENCIA DE DIVERSOS IONS}

Em primeiro lugar foi estudada a influência do ín amônio. $\mathrm{O}$ quadro 2 resume os dados obtidos com o mencionado ion na forma de $\mathrm{NH}_{4} \mathrm{NO}_{3}$.

$$
\text { QUADRO } 2
$$

Influência do íon amônio sôbre a determinaçăo do cálcio.

\begin{tabular}{cccccccc}
\hline \multirow{2}{*}{$\mathrm{NH}_{4}$ t. em ppm } & \multicolumn{6}{c}{ Concentração da solução em ppm de cálcio } \\
& 0 & 20 & 40 & 60 & 80 & 100 \\
\hline 0 & leit. & leit. & leit. & leit. & leit. & leit. \\
360 & 0 & 20 & 41 & 60 & 81 & 100 \\
900 & 0 & 20 & 40 & 61 & 80 & 100 \\
& 0 & 20 & 40 & 60 & 81 & 100
\end{tabular}

Pode-se observar pelos dados do quadro 2 , que o íon amônio não exerceu qualquef influência na determinação do cálcio dentro dos limites de concentração estudados. 
A interferência de outros ions, tais como ferro, alumínio, manganês, magnésio, sódio, potássio e fosfato, sôbre a determinação do cálcio em solução $0,02 \mathrm{~N}$ em $\mathrm{NH}_{4} \mathrm{NO}_{3}$, preparada conforme já foi descrita, pode ser observada no quadro 3 .

QUADRO 3

Influência de diversos ions, sôbre a determinação do cálcio em solução $0,02 \mathrm{~N}$ em $\mathrm{NH}_{4} \mathrm{NO}_{3}$.

\begin{tabular}{|c|c|c|c|c|}
\hline $\begin{array}{c}\text { İon colocado } \\
\text { em ppm }\end{array}$ & $\begin{array}{c}\text { Concentraçăo } \\
0 \mathrm{ppm}\end{array}$ & $\begin{array}{l}\text { de cálcio } \\
50 \mathrm{ppm}\end{array}$ & $\begin{array}{c}\text { Cálcio deter- } \\
\text { minado em } \\
\text { ppm }\end{array}$ & $\begin{array}{c}\text { Desvio } \\
\text { porcentual }\end{array}$ \\
\hline $\begin{array}{c}0 \\
\text { manganês }\end{array}$ & $\begin{array}{c}\text { leit. } \\
0\end{array}$ & $\begin{array}{l}\text { leit. } \\
50\end{array}$ & 50 & - \\
\hline 4 & 0 & 49 & 49 & -2 \\
\hline 8 & 0 & 50 & 50 & 0 \\
\hline $\begin{array}{c}12 \\
\text { magnésio }\end{array}$ & 0 & 49 & 49 & -2 \\
\hline 10 & 0 & 50 & 50 & 0 \\
\hline 20 & 0 & 50 & 50 & 0 \\
\hline $\begin{array}{c}50 \\
\text { potássio }\end{array}$ & 0 & 50,5 & 50,5 & +1 \\
\hline 4 & 0 & 50 & 50 & 0 \\
\hline 8 & 0 & 50 & 50 & 0 \\
\hline 16 & 0 & 50 & 50 & 0 \\
\hline sódio & & & & \\
\hline 2 & 0 & 50 & 50 & 0 \\
\hline 4 & 0 & 50 & 50 & 0 \\
\hline 8 & 0 & 50 & 50 & 0 \\
\hline ferro & & & & \\
\hline 50 & 1 & 51 & 51 & $+2^{\circ}$ \\
\hline 100 & 2 & 52 & 52 & +4 \\
\hline $\begin{array}{c}200 \\
\text { alumínio }\end{array}$ & 5 & 55 & 55 & +10 \\
\hline 50 & 0 & 28 & 28 & -44 \\
\hline 100 & 0 & 22 & 22 & -56 \\
\hline 200 & 0 & 20 & 20 & -60 \\
\hline fosfato & & & & \\
\hline 2 & 0 & 42 & 42 & -16 \\
\hline 4 & 0 & 42 & 42 & -16 \\
\hline 10 & 0 & 40 & 40 & -20 \\
\hline
\end{tabular}


Pelo exame do quadro 3, pode-se concluir, que os cátions manganês, magnésio, potássio e sódio não afetaram a determinação do cálcio nos níveis estudados.

O cátion ferro, a partir de $100 \mathrm{ppm}$, afetou a determinação do cálcio, elevando as leituras. Com $200 \mathrm{ppm}$ de ferro e $50 \mathrm{ppm}$ de cálcio, a leitura obtida foi de 55 , que correspondeu a um desvio porcentual de $+10 \%$ de cálcio existente.

$\mathrm{O}$ aluminio e o fosfato deprimiram as leituras. $\mathrm{O}$ alumínio mesmo na proporção de $50 \mathrm{ppm}$ causou um desvio porcentual de $-44 \%$, quando em presença de $50 \mathrm{ppm}$ de cálcio. O ânion fosfato na proporção de $2 \mathrm{ppm}$ de $\mathrm{PO}_{4}-$ para $50 \mathrm{ppm}$ de $\mathrm{Ca}++$, deterterminou um desvio porcentual de $-16 \%$.

Deve ser salientado, que as concentrações estudadas para os ions interferentes, foram calculadas em função de teor considerado alto para os solos do Estado de São Paulo (CATANI \& GALLO, 1951; CATANI, GALLO \& GARGANTINI, 1955).

\subsection{DETERMINAÇÃO DE CÁLCIO «TROCAVEL»}

Considerando-se os resultados obtidos no estudo da influência de diversos ions sôbre a determinação do cálcio, procurou-se eliminar os citados ions pela precipitação com hidróxido de amônio e água de bromo, conforme técnica já descrita.

Os dados obtidos na determinação do cálcio "trocável" em 10 amostras de solos de diversos tipos são apresentados no quadro 4. Nèsse quadro são mostrados os resultados obtidos empregando-se o método permaganométrico e o baseado em fotometria de chama.

Conforme evidenciam os dados apresentados, o método baseado na fotometria de chama se equivale ao permanganométrico na determinação do cálcio "trocável", segundo a técnica proposta. Entretanto deve ser acentuado que a rapidez do método fotométrico supera em muito o volumétrico.

\section{RESUMO}

O presente trabalho relata o método de determinação do cálcio "trocável" dos solos do Estado de São Paulo, baseado na fotometria de chama.

O método baseado na fotometria de chama foi comparado com o permanganométrico, através da determinação do cálcio "tro- 


\section{QUARDO 4}

Cálcio «trocável» em solos, determinado pelo método permanganométrico e por fotometria de chama (média de 5 repetiçôes).

\begin{tabular}{ccc}
$\begin{array}{c}\text { Solo } \\
\text { n.o }\end{array}$ & $\begin{array}{c}\text { Permanganometria } \\
\text { e.mg/100 g de solo }\end{array}$ & $\begin{array}{c}\text { Fotometria de chama } \\
\text { e.mg/100 g de solo }\end{array}$ \\
\hline 1 & $3,58 \pm 0,004$ & $3,75 \pm 0,040$ \\
2 & $2,60 \pm 0,059$ & $2,53 \pm 0,026$ \\
3 & $0,54 \pm 0,025$ & $0,69 \pm 0,034$ \\
4 & $0,39 \pm 0,036$ & $0,37 \pm 0,020$ \\
5 & $3,61 \pm 0,027$ & $3,22 \pm 0,044$ \\
6 & $9,41 \pm 0,038$ & $9,40 \pm 0,074$ \\
7 & $1,00 \pm 0,000$ & $0,93 \pm 0,001$ \\
8 & $1,79 \pm 0,032$ & $1,53 \pm 0,069$ \\
9 & $1,00 \pm 0,000$ & $0,92 \pm 0,000$ \\
10 & $0,60 \pm 0,027$ & $0,58 \pm 0,033$ \\
\hline
\end{tabular}

cável" em 10 amostras de terra, tendo sido feitas 5 repetições com cada método.

Foi estudada também a influência de diversos ions (magnésio, manganês, potássio, sódio, ferro, alumínio e fosfato) na determinação do cálcio por fotometria de chama.

O método de determinação do cálcio "trocável" do solo, baseado em fotometria de chama forneceu resultados equivalentes ao método permanganométrico, com enorme vantagem na rapidez.

\section{CONCLUSÕES}

Os dados obtidos permitem concluir que:

a) Os ions amônio, sódio, potássio, manganês e magnésio não exerceram influência na determinação do cálcio por fotometria de chama, quando presentes nas concentrações estudadas.

b) Os íons ferro, alumínio e fosfato afetaram a determinação do cálcio.

c) O método de determinação do cálcio "trocável" do solo baseado em fotometria de chama apresentou precisão equivalente ao método permanganométrico. 
Entretanto, o método da fotometria de chama é muito mais rápido do que o permanganométrico, permitindo a execução de um número mais elevado de determinações na mesma unidade de tempo.

\section{SUMMARY}

This paper describes the determination of exchangeable calcium in soils, by the flame photometric method.

A study was made concerning the interference of several ions on calcium determination by flame photometry. Iron, aluminum and phosphate interfere, when present in concentration considered high for the soils of the State of São Paulo, Brazil.

In order to compare the flame photometric method with the permanganometric method for determining exchangeable calcium, five replications of ten soils were analysed by both methods. The ions that interfere (iron, aluminum, phosphate, etc.) were separated by ammonium hydroxide and bromine and the data obtained allow to conclue that the two methods are equivalente.

\section{LITERATURA CITADA}

BURRIEL-MARTI \& RAMIREZ MUÑOZ, 1957 - Flame photometry. Elsevier Publishing Company. New York, 531 pp.

CATANI, R. A. \& R. GALLO, 1951 - A extraç̃̃o do manganês e suas formas de ocorréncia em alguns solos do Estado de São Paulo. Bragantia, 11: 255-266.

CATANI, R. A., J. ROMANO GALLO \& H. GARGANTINI, 1955 Amostragem de solo, métodos de análise, interpretação e indicações gerais para fins de fertilidade. Boletim 69, 28 pp. Instituto Agronômico de Campinas.

CATANI, R. A. \& A. KUPPER, 1949 - As formas «trocável» e «fixa» dos cations $\mathrm{K}$, Ca e Mg nos solos do Estado de São Paulo. Bragantia, 9, $185: 192$.

DINNIN, J. 1., 1960 - Releasing effects in flame photometry. Determination of calcium. Anal. Chem., 32, 1475-1478.

PRATT, P. F. \& G. R. BRADFORD, 1960 - Determination of exchangeable cations in soils with the Beckman Model B flame spectrophotometer, Soil Science 89, 342-346.

WILLIAMS, C. H., 1960 - The use of lanthanum chloride to prevent interferences in flame photometry. Determination of exchangeable calcium in soils. Analytica Chimica Acta, 22, 163:171. 
